\title{
Links Between Annual, Milankovitch and Continuum Temperature Variability
}

\section{Citation}

Huybers, Peter J., and William Curry. 2006. Links between annual, Milankovitch and continuum temperature variability. Nature 441: 329-332.

\section{Published Version}

http://dx.doi.org/10.1038/nature04745

\section{Permanent link}

http://nrs.harvard.edu/urn-3:HUL.InstRepos:3382979

\section{Terms of Use}

This article was downloaded from Harvard University's DASH repository, and is made available under the terms and conditions applicable to Other Posted Material, as set forth at http:// nrs.harvard.edu/urn-3:HUL.InstRepos:dash.current.terms-of-use\#LAA

\section{Share Your Story}

The Harvard community has made this article openly available.

Please share how this access benefits you. Submit a story.

\section{Accessibility}




\title{
Links between annual, Milankovitch and continuum temperature variability
}

\author{
Peter Huybers $^{1} \&$ William Curry ${ }^{1}$
}

\begin{abstract}
Climate variability exists at all timescales_-and climatic processes are intimately coupled, so that understanding variability at any one timescale requires some understanding of the whole. Records of the Earth's surface temperature illustrate this interdependence, having a continuum of variability following a power-law scaling ${ }^{1-7}$. But although specific modes of interannual variability are relatively well understood ${ }^{8,9}$, the general controls on continuum variability are uncertain and usually described as purely stochastic processes $^{10-13}$. Here we show that power-law relationships of surface temperature variability scale with annual and Milankovitchperiod (23,000- and 41,000-year) cycles. The annual cycle corresponds to scaling at monthly to decadal periods, while millennial and longer periods are tied to the Milankovitch cycles. Thus the annual, Milankovitch and continuum temperature variability together represent the response to deterministic insolation forcing. The identification of a deterministic control on the continuum provides insight into the mechanisms governing interannual and longer-period climate variability.
\end{abstract}

Relative to the annual and Milankovitch cycles ${ }^{14,15}$, the continuum of climate variability has received little attention, but is nonetheless expected to embody a rich set of physical processes ${ }^{12}$. We focus on the continuum of surface temperature variability because of its pertinence to society and because of the relative abundance of records. The continuum can be described using spectral power laws: $P(f) \propto f^{-\beta}$, where $P$ is spectral energy, $f$ is frequency, and $\beta$ is the power law. Power laws arise in physical systems as a result of nonlinearities transferring energy between different modes.

At interannual and decadal timescales, surface temperatures exhibit a strong land-sea contrast, with $\beta$ averaging one over the oceans and zero over the continents ${ }^{3-5}$. At millennial and longer timescales, ice-core and marine palaeoclimate records indicate $\beta$ is closer to two $^{1,3,6,7,12}$. Thus, long-period temperature variability has a larger $\beta$ than does short-period variability, with a transition occurring near centennial timescales. Note that ice-core palaeodata resolve timescales both shorter and longer than centennial periods, and demonstrate a change in the power law near centennial periods ${ }^{2,3}$.

Numerous explanations have been advanced regarding the continuum, including stochastic resonance ${ }^{11}$, modified random walks ${ }^{12}$, and diffusion ${ }^{13}$, but all these models are partial descriptions of the variability. Ultimately, one seeks a physics of climate from which the temperature spectrum can be deduced, something analogous to oceanography's theories for tides ${ }^{16}$ and internal waves ${ }^{17}$. Further analysis of the continuum is expected to aid in distinguishing the processes that control climate change.

We use Thomson's multitaper method ${ }^{18}$ to estimate the surface temperature spectra (see Methods). Surface air temperatures (values at $2 \mathrm{~m}$ above the surface) from the NCEP-NCAR instrumental reanalysis ${ }^{19}$ are analysed from 1948 to 2002 and show, as expected, that $\beta$ is smaller over land ${ }^{4,5}$. Not previously documented is that $\beta$ is also smaller toward high latitudes. For comparison, the average land-sea contrast in $\beta$ is 0.2 , while the average Equator-to-pole difference is one. The average standard error in individual estimates of $\beta$ is \pm 0.16 .

The spatial patterns associated with $\beta$ and the annual cycle mirror one another (Fig. 1). Zonally, the annual amplitude is smallest at the Equator, steeply increases to mid-latitudes, and then more gradually increases toward the poles; $\beta$ has the opposite pattern. The Southern Hemisphere has a smaller annual amplitude and larger $\beta$ than the Northern Hemisphere, presumably because of the greater ocean area. Similarly, the greater marine influence on the western margins of North America and Eurasia leads to a smaller annual amplitude and larger $\beta$ than in the east.

Tropical ocean surface temperatures generally have a large $\beta$ and a small annual cycle. That the largest values of $\beta$ occur in the eastern equatorial Pacific is probably due to the El Niño variability. Note that El Niño does not obey a power law, but rather increases estimates of $\beta$ by superimposing energy on the continuum at two- to five-year periods ${ }^{8}$. The presence of El Niño variability is also why the largest standard errors in $\beta, \pm 0.3$, occur in the eastern equatorial Pacific. The relatively large annual cycles in the eastern equatorial Pacific and Atlantic are primarily due to seasonal changes in upwelling ${ }^{20}$.

The close relationship between the spectral energy at annual periods and the continuum is also evident when spectra are binned and averaged according only to annual period energy (Fig. 1e). Bins are designated from minimum to maximum annual energy at intervals of $0.2 \log _{10}\left[{ }^{\circ} \mathrm{C}^{2} \mathrm{ds}^{-1}\right]$ (where ds is spectral bandwidth; see Methods) and, on average, contain 780 individual spectra. $\beta$ decreases with the annual period energy, $P_{1}$, as $\beta=-0.26 \log _{10}\left(P_{1}\right)+0.81$. The cross-correlation between $\beta$ and $\log _{10}\left(P_{1}\right)$ is -0.98 . Although $\beta$ decreases with increasing $P_{1}$, the average spectral energy between periods of 1.1 and 30 years, $\bar{P}$, actually increases. For spectral estimates with $P_{1}>1$, interannual and annual period energy are related as $\log _{10}(\bar{P})=0.58 \log _{10}\left(P_{1}\right)+2.05$ with a cross-correlation of 0.99 . Thus the three primary features of the instrumental temperature spectra (the power law, annual period energy, and interannual energy) are all tightly linked. Analysis of an instrumental compilation of surface temperatures ${ }^{21}$ yields similar relationships.

Further indication of a link between the annual cycle and the continuum comes from auto-bicoherence in surface temperature variability. Nonlinear interactions often produce phase dependencies between different frequencies. Auto-bicoherence measures nonlinear interaction by comparing the phase of two frequencies with the phase of their sum and difference frequencies ${ }^{22}$. An estimate of the global auto-bicoherence of surface air temperatures is obtained by averaging 330 individual estimates made using those records in an instrumental compilation ${ }^{21}$ having over $99 \%$ data coverage during the last century. A highly significant auto-bicoherence $(p=0.01)$ is found between the annual period and nearly all longer periods (Fig. 1f), supporting the inference that the temperature continuum is closely linked to the annual cycle. This bicoherence pattern can be

${ }^{1}$ Woods Hole Oceanographic Institution, Woods Hole, Massachusetts 02543, USA. 

a $\begin{aligned} & -2 \\ & -1 \\ & -1 \\ & -2\end{aligned}$

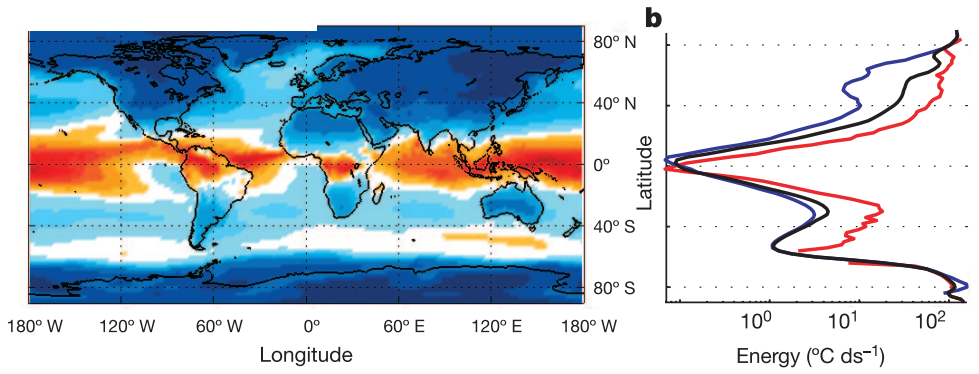

c
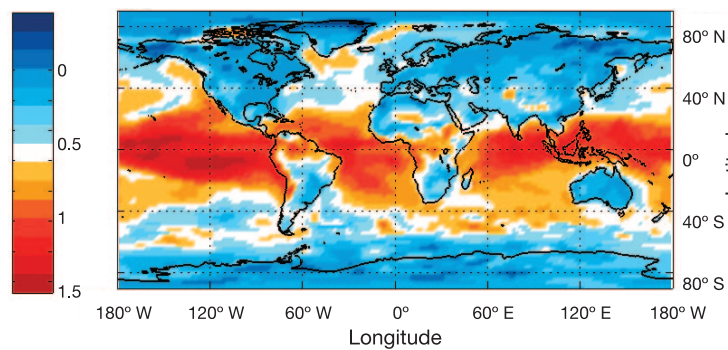

d

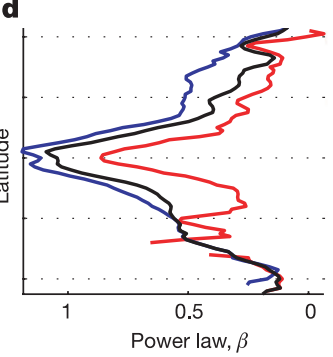

e

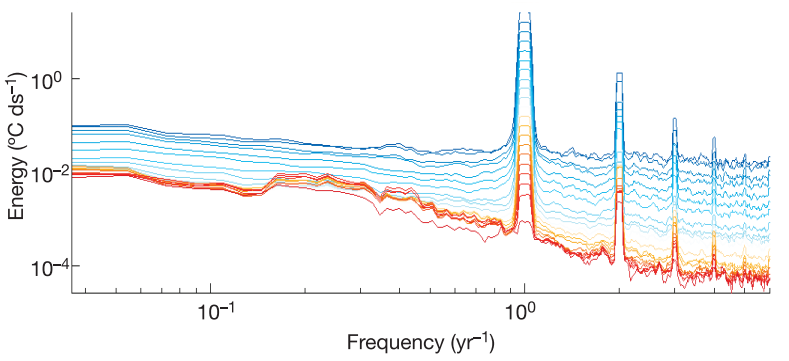

,

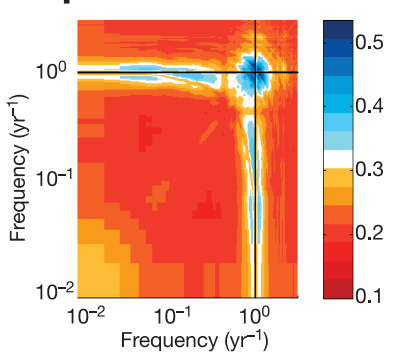

Figure 1 Temperature scaling at instrumental periods from NCEP. a, Map of the spectral energy at the annual period in $\log _{10}$ units, and $\mathbf{b}$, the zonal average (black) along with land-only (red) and ocean-only (blue) averages. c, $\beta$ computed between two months and 30 years after removing the annualperiod energy and its higher harmonics, and $\mathbf{d}$, the associated zonal averages. Note that the colour scale in $\mathbf{c}$ and $x$ axis in $\mathbf{d}$ are reversed.

modelled using multiplicative noise. For example, if weather variations are modelled as a stochastic white noise process and then multiplied by an annual cycle such that variability is greater during the winter, an auto-bicoherence pattern similar to Fig. $1 \mathrm{f}$ is obtained.

The two regions having the greatest contrast in temperature spectra are the tropical oceans and the high-latitude continents (Fig. 1). To trace the behaviour of these contrasting environments out to longer timescales, two separate sets of palaeorecords are compiled, one from each region, both spanning monthly to million-year timescales (see Fig. 2 and Supplementary Information). Although noise and other climatic effects are present, the simplest interpretation of each palaeorecord is as a proxy for temperature. Spectral estimates at most frequency bands are available from at least two independent proxies and agree well with one another, providing confidence in the result. We first discuss the concentrations of spectral energy (that is, the peaks) in the proxy temperature spectrum and then the continuum.

Both the high-latitude and tropical spectra show significant $(p=0.05)$ spectral peaks associated with insolation forcing. At high latitudes, the annual cycle is massive, accounting for $80 \%$ of the variance at monthly to million-year timescales, while in the tropics the annual cycle accounts for only $25 \%$ of the total variance. Periods longer than $10 \mathrm{kyr}$ contain $10 \%$ of the high-latitude variance and $50 \%$ of the tropical variance. At long periods, a $23-\mathrm{kyr}$ precession period is found in tropical planktonic $\delta^{18} \mathrm{O}$ records and, to a lesser extent, $\mathrm{Mg} / \mathrm{Ca}$ records. 41-kyr obliquity variations are directly present in the insolation forcing, and correspond to peaks in tropical e, Spectra binned according to annual-period energy and averaged. Line colours correspond to the colour scale in $\mathbf{a}$. The $\beta$ and average magnitude of the continuum both scale with the amplitude of the annual cycle. $f$, Autobicoherence estimate of instrumental surface air temperatures ${ }^{21}$. The approximate $99 \%$ confidence level is 0.3 . Black lines indicate the annual cycle.

planktonic $\delta^{18} \mathrm{O}$, tropical alkenone, and high-latitude ice-core $\delta^{18} \mathrm{O}$ records. The most energetic low-frequency band is associated with the $\sim 100$-kyr glacial cycles.

Turning now to the continuum of temperature variability, between annual and centennial periods the tropical marine compilation has $\beta=0.56 \pm 0.08$ while the high-latitude compilation has $\beta=0.37 \pm 0.05$, both in agreement with results shown in Fig. 1 . The magnitudes of the tropical and high-latitude spectra approach one another on moving from annual to longer periods and nearly converge at centennial periods. At periods longer than centuries, however, steeper power-law relationships exist. In the tropics $\beta=1.29 \pm 0.13$ and at high latitudes $\beta=1.64 \pm 0.04$. With this change in slope the spectra diverge as one moves from centennial to longer timescales. The tropical and high-latitude continua are most similar at centennial timescales. Conversely, the high-latitude continuum is more than an order of magnitude more energetic near the annual and Milankovitch periods. Apparently, the continuum is more energetic at locations that have greater insolation variability and at timescales neighbouring those of the insolation forcing.

Whereas the annual and Milankovitch-period climate variations tell us primarily about the forcing, the continuum tells us about the dynamical processes governing climate variability. The existence of two separate scaling regimes above and below centennial periods suggests the presence of distinct controls on the climate variability. Possibly, the climate system has a memory associated with the oceans that causes high-frequency variability to accumulate into progressively larger and longer-period variations ${ }^{23}$, and a Milankovitch-driven low-frequency 

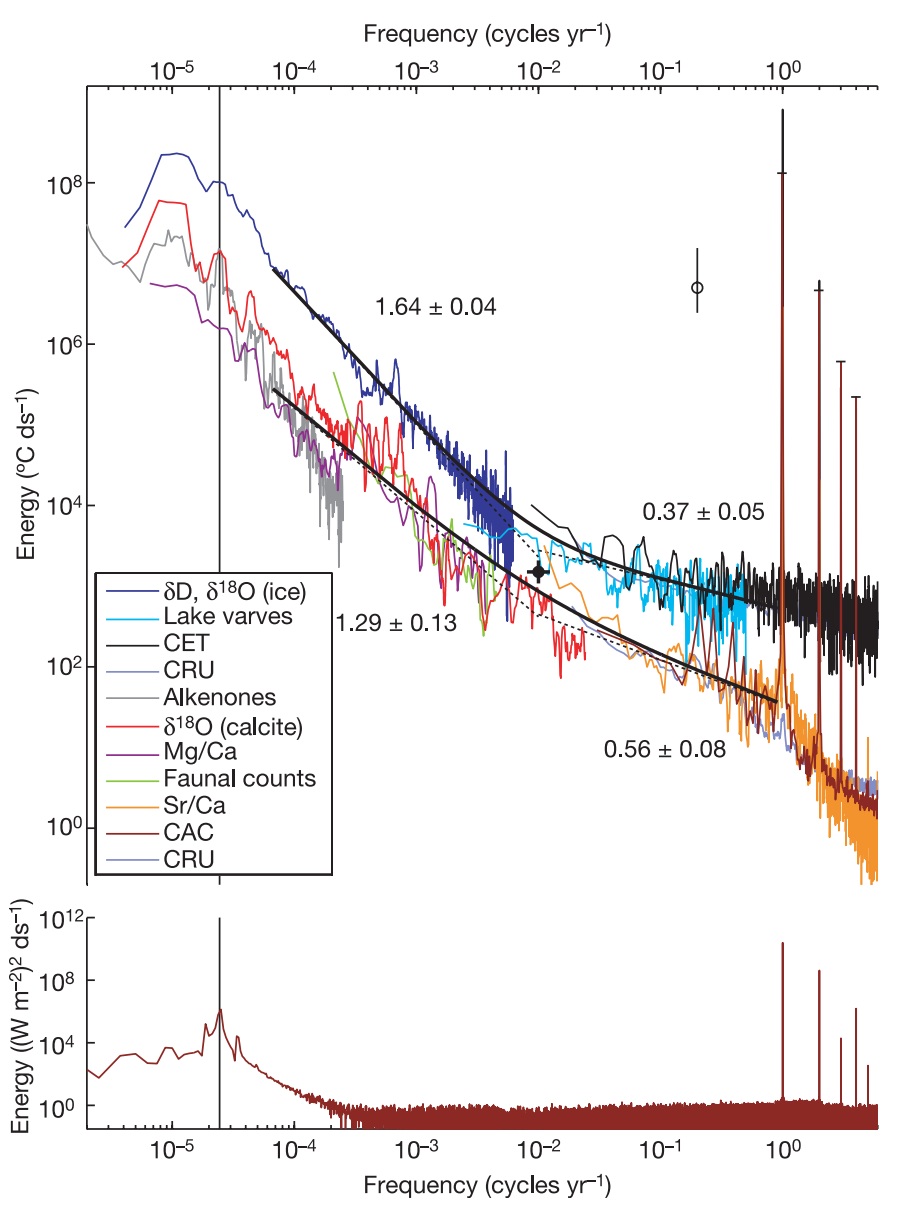

Figure 2 | Patch-work spectral estimate using instrumental and proxy records of surface temperature variability, and insolation at $65^{\circ} \mathrm{N}$. The more-energetic spectral estimate is from high-latitude continental records and the less-energetic estimate from tropical sea surface temperatures. Highlatitude spectra are estimated from Byrd, Taylor and GISP2 ice-core $\delta^{18} \mathrm{O}$; Vostok and Dome $\mathrm{C}$ ice-core $\delta \mathrm{D}$; Donard lake varve thickness; the Central England Time-series (CET); and the Climate Research Unit's (CRU) instrumental compilation. From low latitudes we use ODP846 marine sediment-core alkenones; W167-79, OCE205-103, EW9209-1, ODP677 and ODP927 calcite $\delta^{18} \mathrm{O}$; PL07-39 and TR163-19 Mg/Ca; ODP658 foram assemblages; Rarotonga coral Sr/Ca; and the Climate Analysis Center (CAC) and CRU instrumental compilations. Temperature spectral estimates from records of the same data type are averaged together $\left(\delta^{18} \mathrm{O}_{\text {ice }}\right.$ and $\delta \mathrm{D}_{\text {ice }}$ are also averaged). Power-law estimates between 1.1-100 yr and 100-15,000 yr periods are listed along with standard errors, and indicated by the dashed lines. The sum of the power-laws fitted to the long- and short-period continuum are indicated by the black curve. The vertical line-segment indicates the approximate $95 \%$ confidence interval, where the circle indicates the background level. The mark at $1 / 100 \mathrm{yr}$ indicates the region mid-way between the annual and Milankovitch periods. At bottom is the spectrum of insolation at $65^{\circ} \mathrm{N}$ sampled monthly over the past million years plus a small amount of white noise. The vertical black line indicates the 41-kyr obliquity period.

response that transfers spectral energy toward higher frequencies, possibly involving nonlinear ice-sheet dynamics. These low- and high-frequency temperature responses appear to be of nearly equal magnitude at centennial timescales, midway in log-frequency space between the annual and Milankovitch bands. Interannual temperature variability may also follow different power laws during glacial and interglacial periods, but assessment of this further possibility awaits a global set of high-resolution glacial climate records.

What would the background continuum look like in the absence of annual or Milankovitch variations? Variations would presumably still exist owing to adjustments in the Equator to pole temperature gradient, providing a background of climate variability upon which variations due to Milankovitch- and annual-period changes are superimposed. The diurnal cycle is also expected to cause a local continuum response, but we have restricted the analysis to the more climatically relevant longer-period responses.

Discussion of long-term climate variability is commonly divided between deterministic ${ }^{15}$ and stochastic components ${ }^{12}$ - often associated with spectral peaks and the continuum, respectively ${ }^{10}$. The analysis presented here indicates that the annual and Milankovitch energy are linked with the continuum, and together represent the climate response to insolation forcing.

These observations have implications for understanding future climate variability. The distinction between the magnitude of lowand high-latitude climate variability ${ }^{24}$ may become smaller toward centennial timescales. Furthermore, the physics controlling centennial and longer-timescale temperature variability appears to be distinct from that of shorter timescales, raising questions of whether climate models able to represent decadal variations ${ }^{25}$ will adequately represent the physics of centennial and longer-timescale climate variability. Finally, because the annual and Milankovitch cycles are deterministic, a greater understanding of their influence on the continuum may lead to improved predictability of interannual and longer-timescale climate variability.

\section{METHODS}

Spectral analysis. Spectra are estimated using Thomson's multitaper method ${ }^{18}$ with three windows. To reduce the influence of a small bias present at the lowest frequencies in the multitaper spectral estimates ${ }^{26}$, the three lowest-frequency estimates are dropped when estimating $\beta$. For palaeorecords, when spectral estimates from the same proxy type overlap, a weighted average is taken. Weightings are proportional to frequency resolution so that better resolved records contribute more heavily. Spectral energy, or more precisely spectral energy density, is measured in ${ }^{\circ} \mathrm{C}^{2} \mathrm{ds}^{-1}$. In this case energy refers to the squared quantity, ${ }^{\circ} \mathrm{C}^{2}$ (not joules), and density refers to energy per unit frequency, ds, where ds equals one over the length of the record in years. The energy density of the spectral continuum is independent of record duration.

The power law, $\beta$, is estimated by a least-squares fit to log-frequency and $\log$ power-density estimates. To more uniformly weight the estimate, spectra are binned into equally spaced log-frequency intervals and averaged before fitting $\beta$. For the instrumental records, monthly anomalies are used when estimating $\beta$ in order to filter out spectral energy associated with the annual cycle and its higher harmonics. To preclude effects from a small residual annual cycle, power-law fits and computation of the average continuum energy exclude frequencies between $1 / 0.8$ to $1 / 1.2 \mathrm{yr}^{-1}$ and $1 / 1.8$ to $1 / 2.2 \mathrm{yr}^{-1}$. For palaeorecords, $\beta$ is estimated between $1 / 100$ and $1 / 15,000 \mathrm{yr}^{-1}$ to minimize the influence from the Milankovitch bands. Uncertainties reported for $\beta$ are the standard error of the least-squares fit. In the case of the auto-bicoherence statistic, the energy contained at each frequency band is first normalized to unity so that only the phase information is retained, thus ensuring that the magnitude of the annual cycle does not bias the result.

The fraction of variance at the annual cycle is calculated by integrating the estimated spectral energy between frequencies of $1 / 0.95$ to $1 / 1.05$ and then dividing by the total spectral energy. The integration accounts for variations in the frequency spacing so that changes in record length do not influence estimates of the energy at the annual period. At high frequencies, only instrumental estimates are used as these are more accurate. Furthermore, tropical $\delta^{18} \mathrm{O}_{\text {calcite }}$ records are excluded to minimize influence from non-temperature effects. To permit direct comparison between the continuum and annual-period energy in Fig. 2, the amplitude of the annual cycle and its harmonics are increased to the expected value for a record one million years in duration.

Another technique commonly used to estimate scaling relationships is detrended fluctuation analysis ${ }^{4,5,7}$ (DFA), which yields a coefficient, $\alpha$, related to the spectral power law by $\alpha=(\beta+1) / 2$. Results presented here were checked using DFA and are in agreement; this is as expected, because DFA and Fourier estimates are mathematically equivalent up to the choice of weighting term $\mathrm{s}^{27}$. For ease of comparison, other authors' DFA results are reported as $\beta$ values. Data. The NCEP reanalysis ${ }^{19}$ of two-metre air temperatures has global coverage but only spans the period 1949 to 2002. Palaeo-temperature proxies are necessary to resolve centennial and longer-period temperature variability. Following ref. 1, we piece together spectral estimates from records of differing durations and resolution. Two separate spectral patchworks of surface air 
temperature are made: one using high-latitude continental records and another using tropical marine records. At high latitudes, $\delta^{18} \mathrm{O}_{\text {ice }}$ ice-core records and lake sediment data constrain surface air temperature variability. Tree-ring records are excluded because low-frequency variability can only be reconstructed over large spatial scales $^{28}$, and this analysis is restricted to localized temperatures. In the tropics, we use foram assemblages, $\mathrm{Sr} / \mathrm{Ca}$ from corals, alkenones, $\delta^{18} \mathrm{O}_{\text {calcite }}$ and $\mathrm{Mg} / \mathrm{Ca}_{\text {calcite }}$ records to constrain sea surface temperature variability. References for the records and pertinent statistics are provided in Supplementary Information.

The entire $\delta^{18} \mathrm{O}_{\text {calcite }}$ signal is converted into temperature variability, not correcting for the ice-volume component, because we expect higher-frequency variability to reflect rapid changes in temperature and no frequency-dependent correction is available. At low frequencies, this leads to an overestimate in the amplitude of $\delta^{18} \mathrm{O}_{\text {calcite }}$ temperatures by roughly a factor of two, but at high frequencies $\delta^{18} \mathrm{O}_{\text {calcite }}$ variability is in good agreement with the other temperature proxies. Spectral power laws are estimated in this higher-frequency region $(>1 / 15 \mathrm{kyr})$, mitigating effects from the ice-volume component of the $\delta^{18} \mathrm{O}_{\text {calcite }}$ variability.

There are numerous uncertainties associated with the interpretation of palaeo-proxies. Uncertainties directly influencing the shape of the spectra include rectification and aliasing ${ }^{29}$ - potentially first order effects, considering that most proxies are affected by but do not resolve the annual variability. Spectral estimates are also subject to errors or assumptions built into the age mode $^{30}$. All records use their published age models except for ODP677 and ODP927 where a depth-derived age-model ${ }^{30}$ is used, not making orbital assumptions.

The scope of error due to non-temperature effects, observational uncertainty, age-model uncertainty, aliasing and rectification is unclear. However, some confidence is provided in that various proxies, sensitive to differing environmental factors and measured at different locations, yield commensurate spectral estimates at most frequency bands. Furthermore, at annual to centennial timescales, the proxies reproduce the same scaling structure evident in the instrumental records.

\section{Received 6 November 2005; accepted 23 March 2006.}

1. Shackleton, N. J. \& Imbrie, J. The $\delta^{18} \mathrm{O}$ spectrum of oceanic deep water over a five-decade band. Clim. Change 16, 217-230 (1990).

2. Ditlevsen, P., Svensmark, H. \& Johnsen, S. Contrasting atmospheric and climate dynamics of the last-glacial and Holocene periods. Nature 379, 810-812 (1996).

3. Pelletier, J. The power-spectral density of atmospheric temperature from time scales of $10^{-2}$ to $10^{6} \mathrm{yr}$. Earth Planet. Sci. Lett. 158, 157-164 (1998).

4. Fraedrich, K. \& Blender, R. Scaling of atmosphere and ocean temperature correlations in observations and climate models. Phys. Rev. Lett. 90, 108501 (2003).

5. Blender, R. \& Fraedrich, K. Long time memory in global warming simulations. Geophys. Res. Lett. 14, doi:10.1029/2003GL017666 (2003).

6. Schmitt, F., Lovejoy, S. \& Schertzer, D. Multifractal analysis of the Greenland Ice-core Project climate data. Geophys. Res. Lett. 22, 1689-1692 (1995).

7. Ashkenazy, Y., Baker, D., Gildor, H. \& Havlin, S. Nonlinearity and multifractality of climate change in the past 420,000 years. Geophys. Res. Lett. 30 doi:10.1029/2003GL018099 (2003).

8. Philander, G. El Niño, La Niña, and the Southern Oscillation (Academic, San Diego, California, 1990).

9. Hurrell, J. \& Van Loon, H. Decadal variations in climate associated with the North Atlantic Oscillation. Clim. Change 36, 301-326 (1997).
10. Kominz, M. \& Pisias, N. Pleistocene climate-deterministic or stochastic? Science 204, 171-173 (1979)

11. Pelletier, J. Coherence resonance and ice ages. J. Geophys. Res. 108, doi:10.1029/2002JD003120 (2003)

12. Wunsch, C. The spectral description of climate change including the $100 \mathrm{ky}$ energy. Clim. Dyn. 20, 353-363 (2003).

13. Fraedrich, K., Luksch, U. \& Blender, R. A 1/f-model for long time memory of the ocean surface temperature. Phys. Rev. E 70, 037301 (2003).

14. Hays, J., Imbrie, J. \& Shackleton, N. Variations in the earth's orbit: Pacemaker of the ice ages. Science 194, 1121-1132 (1976)

15. Imbrie, J. et al. On the structure and origin of major glaciation cycles. 1. Linear responses to Milankovitch forcing. Paleoceanography 6, 205-226 (1992).

16. Wunsch, $\mathrm{C}$. The spectrum from two years to two minutes of temperature fluctuations in the main thermocline at Bermuda. Deep-Sea Res. 19, 577-593 (1972).

17. Garrett, C. \& Munk, W. Internal waves in the ocean. Annu. Rev. Fluid Mech. 80, 291-297 (1979).

18. Percival, D. \& Walden, A. Spectral Analysis for Physical Applications (Cambridge Univ. Press, Cambridge, UK, 1993)

19. Kalnay, E. et al. The NCEP/NCAR 40-year reanalysis project. Bull. Am. Meteorol. Soc. 77, 437-471 (1996)

20. DeWitt, D. G. \& Schneider, E. K. The processes determining the annual cycle of equatorial sea surface temperature: A coupled general circulation model perspective. Mon. Weath. Rev. 127, 381-395 (1999).

21. Jones, P., New, M., Parker, D., Martin, S. \& Rigor, I. Surface air temperature and its variations over the last 150 years. Rev. Geophys. 37, 173-199 (1999).

22. Elgar, S. \& Sebert, G. Statistics of bicoherence and biphase. J. Geophys. Res. 94, 10993-10998 (1989)

23. Hasselmann, K. Stochastic climate models. Part I. Theory. Tellus 6, 473-485 (1976).

24. Serreze, M. C. et al. Observational evidence of recent change in the northern high-latitude environment. Clim. Change 46, 159-207 (2000).

25. Delworth, T. L. et al. Review of simulations of climate variability and change with the GFDL R30 coupled climate model. J. Clim. 19, 555-574 (2002).

26. McCoy, E., Walden, A. \& Percival, D. Multitaper spectral estimation of powe law processes. IEEE Trans. Signal Process. 46, 655-668 (1998).

27. Wilson, K., Francis, D., Wensel, R., Coats, A. \& Parker, K. Relationship between detrended fluctuation analysis and spectral analysis of heart-rate variability. Physiol. Meas. 23, 385-401 (2002)

28. Briffa, K. et al. Low-frequency temperature variations from a northern tree-ring density network. J. Geophys. Res. 106, 2929-2941 (2001)

29. Wunsch, C. \& Gunn, D. A densely sampled core and climate variable aliasing. Geo-mar. Lett. 29, doi:10.1007/s00367-003-0125-2 (2003).

30. Huybers, P. \& Wunsch, C. A depth-derived Pleistocene age-model: Uncertainty estimates, sedimentation variability, and nonlinear climate change. Paleoceanography 19, doi:10.1029/2002PA000857 (2004).

Supplementary Information is linked to the online version of the paper at www.nature.com/nature.

Acknowledgements P.H. was supported by the NOAA Postdoctoral Program in Climate and Global Change. Funding for W.C. was provided by the National Science Foundation, Division of Ocean Sciences. T. Crowley, R. Ferrari, O. Marchal, J. Sachs, D. Steele and C. Wunsch provided useful comments.

Author Information Reprints and permissions information is available at npg.nature.com/reprintsandpermissions. The authors declare no competing financial interests. Correspondence and requests for materials should be addressed to P.H. (phuybers@whoi.edu). 